\title{
Research on the Evolution and Development of Chinese National Vocal Music Art Style
}

\author{
Juanqin Zhu* \\ 1Tianhe University for Elderly Cardes of Guangzhou, China; \\ 2Jinan University, Guangzhou Guangdong 510632,China.
}

\begin{abstract}
With the support of the current social environment, although Chinese national vocal music has been diversified, it also faces many risks. This article mainly discusses the evolution and development of the artistic style of Chinese national vocal music, and found some problems in its development, and put forward some suggestions and plans for these problems. Chinese national vocal music refers to vocal music forms that are different from Western vocal music, such as musical style characteristics. Today, Chinese national vocal music has entered a new journey in the history of development, presenting the development of the times and the prosperity of culture. Keywords:the Evolution ; Development
\end{abstract}

\section{The Evolution of the Artistic Style of Chinese National Vocal Music}

\subsection{Times style}

Looking back to the 1930s, many composers such as Xian Xinghai founded the combination of opera and song that evolved from the singing performances of singers such as Guo Lanying, which is different from the previous art style, and has been accepted by the public. The main form is lyricism. Songs and classics are sung. From a certain point of view, people mistakenly believe that this style is the only form of expression of national vocal style, and its evolved "ethnic singing" was imitated by many enthusiastic groups; it dates back to the 60 s and 70s, when national vocal music Mainly model plays and quotations songs, both in terms of singing method and artistic expression are relatively single; and in the 1980s, national vocal music has really entered a period of development, which is reflected in the greater scope and greater scope of creation of works. Various forms of expression, people pay more attention to the real emotions and spiritual emotional resonance in the works. The main songwriters and representative works include: Wang Ming's "Sister Finds Brother Tears", Gu Jianfen' s "Young Friends Come "Conference" and many other classics. Time has entered the 1990s, with the common development of economy and culture, the artistic style of national vocal music has begun to show its diversification. Reflected in the rise of the main melody works, the representative national vocal music has entered a stage of comprehensive prosperity and development, and it has also been affected by popular music and other aspects, and the national vocal music has also begun to gradually transform.

\subsection{Regional style}

China has a large number of ethnic groups and a large land area, and the geographical environment, customs and cultures of each ethnic group are quite different. This has created the diversity and difference of the national vocal music styles in our country, such as the Mongolian long tune and the Jiangnan minor. Arrangement to lyrics are a manifestation of local customs and culture. In terms of types, my country's national sound art style includes many types such as folk songs, folk art, rap, and opera. Each type is quite rich in local ethnic elements.

\section{On the Future of Chinese National Vocal Music Based on Multiculturalism}

\subsection{Enhancing cultural identity among different ethnic groups}

With today's rapid economic development and continuous social progress, cultural exchanges between China and the world have gradually increased, and exchanges between different ethnic cultures have become more frequent. Therefore, if we want to make our national culture lasting, we need to make continuous innovations. Also absorb the characteristics of other cultures. Promote cultural exchanges between different ethnic groups with different music styles and diversified cultural forms.

Music can be used as a link for people's emotional communication and an important form of transmission in the development of social human culture. Combining national music culture with realism, we must promote the exchange and common development of local music culture and modern culture, so that not only can people understand different national cultures and even customs, but

Copyright (C) 2020 Juanqin Zhu

doi: 10.18282/1-e.v9i4.1691

This is an open-access article distributed under the terms of the Creative Commons Attribution Non-Commercial License (http://creativecommons.org/licenses/by-nc/4.0/), which permits unrestricted non-commercial use, distribution, and reproduction in any medium, provided the original work is properly cited. 
also can strengthen the understanding and understanding of various nationalities. communicate with.

Vocal music art is an important carrier of national cultural exchanges. In today's multicultural background, the country is also vigorously advocating diversified development. The diversified style characteristics and performance forms of music art are always enriching the development of national music art. The cultural identity and inter-ethnic exchanges among ethnic groups play a key role in prosperity and development. Thereby promoting the identification and exchange between national cultures.

\subsection{Create conditions for cross-cultural communication}

Chinese national vocal music has a profound historical and cultural background. In the long history, in contrast to today's major art academies, Western vocal music has been taught in the classrooms of major art academies in China, and its popularity is increasing year by year. It comes from Italy and France. Vocal music works in other countries have become a compulsory or elective course for art students today. This is because of the standardization and systematization of Western vocal music. Today's students also have a certain understanding of Western culture and language, and some music majors have been established. Special bel canto classrooms can also promote the improvement and study of vocal music. On the basis of combining bel canto, Chinese national vocal music does not forget the characteristics of the national style, improves our national singing skills and enriches its connotation. Therefore, we believe that on the basis of combining the customs and cultures of various ethnic regions, we will absorb the essence of Western music culture and combine the two to promote the long-term development of national vocal art.

The development of folk songs is also constantly improving, and its ultimate goal is to bring Chinese vocal music to the world. With continuous efforts and innovations, Chinese singers have led the characteristics of national vocal music to the world, and further strengthened its communication and inheritance. For example, Peng Liyuan held concerts in Singapore, and well-known Chinese singer Song Zuying also held concerts with Chinese national characteristics in Australia. These prove that Chinese singers are leading the songs rich in national culture to the world. Through incomplete surveys and statistics, more and more singers are bringing Chinese national vocal music to the world stage. It reflects the progress and inheritance of national vocal music development, and at the same time provides a platform for communication and inheritance of national music in our country. Let more people in the world see the progress of Chinese national vocal art.

\subsection{Promoting the Prosperity and Development of Chinese National Vocal Music}

Vocal performance is a form of artistic performance, which is of great significance to the development of national music in our country. More and more singers are devoted to the inheritance and development of national vocal music, which further reflects its importance. In the diversified value of works At the same time as the improvement, the audience understands the innovative development of national vocal music while watching, and their own appreciation level will also be improved.

From a long-term perspective, if my country's national vocal music wants to have a more long-term development, it is necessary to improve the appreciation level of the people and the continuous innovation of vocal music. National vocal music should strengthen the continuous in-depth research and innovation of the content and performance style of the work. At the same time, we found that diversified national vocal music styles can not only benefit his inheritance and development, but also attract more audiences. If it is just a simple folk song, it can only be appreciated in front of art-related students. With the diversification of folk songs, the number of hobby groups has increased, and the popularity of the public has also increased. For example, in a music audition of Hunan Satellite TV in 2018, Gong Shuang, a second-year graduate student, won the annual championship with a multi-element folk song. Along the way, we found that Gong Shuang, as a folk singer, was positive The original classic works were adapted and innovated, and presented to more audiences using relevant platforms. Modern popular accompaniment and western bel canto were also added, which were supported by the judges and the audience.

\section{Suggestions on the Development of Chinese National Vocal Music Art Style}

\subsection{Grasp the singing style of national vocal music}

Generally speaking, the national vocal music has its own strong local characteristics and customs and culture, so, the singer to the song national culture, customs and customs, such as in-depth research and investigation, we should pay special attention to the uniqueness of national vocal music, can not copy nor learn the surface.

\subsection{The combination of nationality and science}

National vocal music should give full play to its local characteristics and study the singing skills and customs and culture of all ethnic groups in depth. For example, Jin Lin integrates scientific singing into national songs, and Wu Xia combines folk songs and operas with strong styles.

\subsection{Learn from other musical styles}

The development of national vocal music should follow the pace of the development of world music culture, select the essence and remove the dross, according to the vocal art form of each region. For example, "Qianmen Qingsi Big Bowl of Tea" combines Peking Opera with popular songs, which can not only attract more music lovers, but also promote the inheritance of national culture.

\section{Conclusion}

To sum up, the development of national vocal art style must be based on traditional culture and local customs, on the basis of maintaining the original national art style, combining the advantages of Western music culture, continuous progress of the times, and social progress.

\section{References}




\title{
Design and Implementation of Virtual Interaction in Tangzha Ancient Town
}

\author{
Jiaxin Tang*, Changyong Zhu, Shizhen Zhou \\ Nantong Institute of Technology Nantong, Jiangsu 226002,China.
}

Abstract:In recent years, as social and economic progress and living standard of people increases, increasing number of people has financial conditions to relax by travelling, but a host of major cultural tourist attractions are seriously damaged due to natural or human reasons, hence, we are constrained by offline and firsthand travelling experience. The high-speed development of internet technology and continuous improvement of computer software and hardware pave the way for the development and application of virtual reality technology, thus generating a kind of brand-new travelling that is appealed to young man. This article studies the combination of virtual reality technology and cultural tourism resources, taking Tangzha Ancient Town, the first industrial town of Nantong as the pilot.

Keywords: Virtual Reality, Cultural Tourism; Virtual Travelling.

Virtual Reality (hereinafter refers to VR) is a human-computer interface technology that highly simulates human, object and environment in the real world, as well as human's visual, auditory and action behaviors in the environment ${ }^{[1]}$. A virtual simulation environment is generated by a computer, which enables users to immerse themselves in the environment and to create a sense of being there ${ }^{[2]}$. Therefore, it is also known as magic mirror technology or artificial environment. This technology covers a variety of subjects, integrating the real world with virtual world through artificial intelligent, computer graphics, sensing and information capture, human-computer interaction, and among others, thus forms a high-tech simulation system that can interact with human beings.

The VR technology has been widely used in various fields. In industrial simulation, a complete simulation system is built by combining user business, data base and data, which can greatly improves the ability of enterprises to collect, analyze and process data and improves the development efficiency of enterprises; in the field of heritage restoration, build 3D model data base (that is digital twin model ) according to the information result of data collection, which can recover the endangered cultural relics with high precision and preserve it in a scientific and permanent way, and rise a new level for exhibiting and protecting cultural relics. In the world of teaching, creating an environment of "autonomous learning", which will replace the traditional learning mode of "promoting learning by teaching" with the new teaching mode of acquiring knowledge and skills through the interaction between itself and the information environment. It will not only save costs, but also enhance learning interests, which is a leap in the development of education. Virtual digital campus is also a manifestation of virtual reality in the field of education.

VR mainly relates to computer graphics image processing technology, virtual engine development platform, polygon modeling, computer programming technology, the human-computer interaction technology, and other technologies, in the interaction system development of virtual town, we use diversified computer processing technologies to product this project, which will be described in detail in the paper.

\section{Development Requirements of Project}

The development requirement of project is to design a virtual travelling interaction system, through which we provide online virtual travelling experience to advertise and promote the tourism attraction, which can facilitate the increase of offline tourism flow.

Copyright (C) 2020 Tang Jiaxin et al.

doi: $10.18282 / 1-$ e.v9i4.1692

This is an open-access article distributed under the terms of the Creative Commons Attribution Non-Commercial License (http://creativecommons.org/licenses/by-nc/4.0/), which permits unrestricted non-commercial use, distribution, and reproduction in any medium, provided the original work is properly cited.

[1]Zhao Shilan. The Evolution and Development of the Artistic Style of Chinese National Vocal Music[J]. Journal of Liaoning Normal University(Social Science Edition). 2005, 03:81-84.

[2]Lai You. Analysis of the Pluralistic Characteristics of the Development of National Vocal Music Art[J]. Music creation. 2017, 01:110-111.

[3]Wang Min. The concept of national vocal music and its style[J]. Journal of Nanjing University of the Arts (Music and Performance). 2017,04:111-115.

[4]Yu Dugang. Vocal Education[M]. Shanghai Music Publishing House. 2009, 05. 